\title{
Pathogenicity and amino acid sequences of hemagglutinin cleavage site and neuraminidase stalk of differently passaged H9N2-avian influenza virus in broilers
}

\author{
Houssam A. Shaib ${ }^{1}$, Nelly Cochet ${ }^{2}$, Thierry Ribeiro ${ }^{3}$, Afif M. Abdel Nour ${ }^{3}$, Georges Nemer ${ }^{4}$, \\ Maya F. Saade ${ }^{1}$, Elie K. Barbour ${ }^{1 *}$
}

\footnotetext{
${ }^{1}$ Department of Animal and Veterinary Sciences, Faculty of Agricultural and Food Sciences, American University of Beirut (AUB), Beirut, Lebanon;

${ }^{2}$ Department of Biological Engineering, Université de Technologie de Compiègne, Compiègne, France;

${ }^{3}$ Institut Polytechnique LaSalle Beauvais, Beauvais, France;

${ }^{4}$ Department of Biochemistry, Faculty of Medicine, American University of Beirut, Beirut, Lebanon.

E-mail: "eb01@aub.edu.lb
}

Received 14 February 2011; revised 21 July 2011; accepted 31 July 2011.

\section{ABSTRACT}

Low pathogenic Avian Influenza (AI) virus has the ability to evolve to high pathogenic viruses resulting in significant economic losses in the poultry sector. This study aims at assessing the impact of H9N2 viral passaging in broilers and its relatedness to pathogenicity and amino acid (a.a) sequences of the hemagglutinin (HA) cleavage site and neuraminidase (NA) stalk. The original H9N2 AI virus (P0) was used to challenge ten-21 days old broilers. Individual recovery of H9N2 virus from homogenates of trachea, lungs and airsacs was attempted in 9 days old chicken embryos, as a conclusion of the first passage (P1). Tracheal isolates of H9N2 were passaged for a second (P2) and a third (P3) time in broilers, followed by a similar embryonic recovery procedure. The a.a. sequence of a part of HA1 cleavage site and Neuraminidase stalk were compared among the differently passaged viruses; an assessement of the relatedness of the determined a.a. sequences to the pathogenicity in broilers, based on frequency of mortality, morbidity signs, gross and microscopic lesions at 3 days post challenge with the P1, P2, and P3-H9N2, is concluded. An increase in certain morbidity signs and specific lesions was observed in P2- and P3-H9N2 challenged broilers compared to birds challenged with P1-H9N2. A conserved R-S-S-R amino acid sequence at the HA1 cleavage site was observed in the differently passaged H9N2, associated with a variability in the NA stalk-a.a sequences. The passaging of the low pathogenic H9N2 virus in broilers leads to a trend of increase in pathogenicity, manifested in higher fre- quency of morbidity signs, and of specific gross and microscopic lesions of the examined organs. This passaging was associated with a conserved a.a. sequence of the hemaglutinin cleavage site and a variability in the sequence of the neuraminidase stalk. A detailed study of the potential of the detected variability in the neuraminidase stalk of H9N2 in induction of a higher pathogenicity in broilers will be the subject of future investigations.

Keywords: H9N2 Avian Influenza; Pathogenicity; Passaging; Broilers; Amino Acid Sequences; Hemagglutinin (HA); Neuraminidase (NA) Stalk

\section{INTRODUCTION}

The H9N2 Avian Influenza (AI) virus infects a wide variety of wild birds and domestic poultry in many parts of the world [1-4], causing significant economic losses, due to increased mortality and morbidity frequency among broilers, layers and breeders [5]. The circulation of AI viruses among wild birds and poultry resulted in the emergence of pathogenic strains originating from low or mild pathogenic viruses [6,7]. The incomplete cleaning and disinfection of poultry houses and hatcheries result in the persistence of AI viruses in organic premices and waste, leading into its passaging or transmission to the next flock [8]. Mixing birds of different species or ages might lead to the circulation of AI viruses and possible reassortment of such strains [8-10].

The pathogenicity of AI viruses increases upon passaging due to an increase in the adaptation to the host $[7,8]$. Consequently, the low pathogenic strains, originally failing to replicate efficiently in the host tissues, gra- 
dually increase their ability to bind to the specific cell receptors, leading to higher replication efficiency in the host cells $[7,8]$.

There is a meager documentation of the potential of H9N2 viruses in attaining gradual higher pathogenicity, following few amino acid changes that could occur in the Hemagglutinin (HA) protein and/or Neuraminidase (NA) stalk $[1,11,12]$. It is proven that a substitution of arginine in the place of Serine at the -2 position of the HA connecting peptide can produce a basic motif for highly pathogenic viruses (R-S-S-R) [1,11]. This motif is recognized by the host ubiquitous proteases, enabling them to cleave the HA0 to HA1 and HA2, thus leading to a systemic infection of the host tissues by the virus. There is an indication in literature that the length of the NA stalk could have an impact on the viral AI pathogenicity; it is documented that a deletion of few amino acids from the NA stalk, namely at position 38 - 39 and 63 - 65, can convert the low pathogenic AI (LPAI) to highly pathogenic AI (HPAI) viruses [1,10,12]; however, no literature points at the impact of a.a. substitution in NA stalk, in absence of deletions, on gradual raise of pathogenicity in avians.

A change in AI viruses from a low to high pathogenicity nature results in an increase in chicken mortality percent, from $5 \%$ by LPAI infection to $20 \%-100 \%$ in HPAI infections $[5,8,13]$; in addition, the frequency of morbidity signs are increased among birds, including a decrease in feed intake, a decrease in weight and egg production, and a higher frequency of huddling, coughing, sneezing, rales, ocular discharge, and swelling of infraorbital sinuses $[5,8,14]$. This increase in mortality and morbidity frequency is the result of viral dissemination and spreading from the nasal cavity, which is the primary site of infection, to the lower part of the respiratory tract, kidneys, intestines, heart and other visceral organs $[5,8,14$, 15].

A modification in tissue tropism could lead into a higher pathogenicity and more prominent disease signs. Upon mutation of LPAI to HPAI, such viruses acquire pneumotropism, nephrotropism, neurotropism, enterotropism and even exert tropism toward lymphoid tissues $[5,14,15]$. The HPAI viruses replicate within epithelial and endothelial cells of the respiratory organs causing major macroscopic or gross lesions such as tracheitis, lung congestion, airsacculitis, and sinusitis; these replicating viruses could spread through the vascular and lymphoid system to visceral organs causing enteritis, nephritis, splenomegaly, vascular and myocardial damage $[5,9,14-16]$. The frequency of microscopic lesions are also increased, specifically in the respiratory system, causing deciliation and Goblet cells degeneration in the trachea, mucus accumulation and heterophils infiltration in the trachea, lung, and airsacs $[5,16,17]$.

This work studies the impact of the number of viral passages in the respiratory organs of 21-days-old broilers on amino acid sequences of Hemgglutinin 1 (HA1) cleavage site and Neuraminidase (NA) stalk and its relatedness to gradual raise in pathogenicity.

\section{MATERIALS AND METHODS}

\subsection{Original Virus}

The original H9N2 strain (P0), used in this study, is a LPAI virus. This virus was isolated from a broiler chicken during an outbreak in a 40,000 flock size $[2,4]$. Complete typing of H9N2 was concluded at the Central Veterinary Laboratory in Weybridge, UK.

\subsection{H9N2 Passaging in Broilers}

Ten 21 days-old broilers, of the Ross 308 breed, were intratracheally challenged with the original H9N2 AI virus (P0), at $7 \times \mathrm{TCID}_{50} / 0.5 \mathrm{ml}$ inoculum/bird. Another 10 control birds were left free from any viral challenge. Individual recovery of the H9N2 virus from homogenates of trachea, lung, and airsac of experimental and control birds was attempted in 9-days-old embryos, according to previous procedures $[7,18]$, and as a conclusion of the first passage (P1). The success of recovery of the H9N2 virus in embryos was based on presence of allantoic fluid-hemagglutination (HA) activity against chicken-Red Blood Cell suspension of 1.0\%. Allantoic fluids from tracheal inocula, with HA activity, were pooled in equal volume, and was used as an inoculum for a second passage of the H9N2 in another ten 21days-old broilers (P2), leaving 10 birds as controls. The inoculum used was set also at $7 \times \mathrm{TCID}_{50} / 0.5 \mathrm{ml} / \mathrm{bird}$. The same recovery protocol and third passage (P3) procedure were used, as described above.

\subsection{Pathogenicity Assessment}

\subsubsection{Mortality and Morbidity Assessment}

The frequency of mortality and of morbidity signs, including rales, sneezing, swelling of infraorbital sinuses, conjunctivitis, and ocular exudates were observed at 3 days post challenge [19-21] with each of $\mathrm{P} 1, \mathrm{P} 2$, and $\mathrm{P} 3$ H9N2 viruses. Experimental and control broilers, corresponding to the challenge with each of the three differently passaged $\mathrm{H} 9 \mathrm{~N} 2$ viruses, were sacrificed with $\mathrm{CO}_{2}$ at 3 days post the viral incubation period $[19,20]$.

\subsubsection{Gross Lesions}

Gross lesions resulting from the 3 differently passaged H9N2 in broilers were observed and recorded for each bird namely, the occurrence of tracheitis, airsacculitis, lung congestion, and enteritis. Three respiratory system organs namely, trachea, lung, and right thoracic airsac 
were each individually removed asceptically, cut into two sections, one fixed in $10 \%$ formalin for histopathologic observations, while the second section was used for H9N2 viral isolation and propagation in 9 days-old chicken embryos.

\subsubsection{Histopathology}

The histopathological studies on collected organs of experimental and control birds included the use of the $10 \%$ formalin fixed tissue cuts that were subjected to crosssectioning of $4 \mu \mathrm{m}$, followed by $\mathrm{H} \& \mathrm{E}$ staining. The microscopic observation at $1000 \times$ included tracheal deciliation, mucosal hypertrophy, Goblet cell degeneration, mucus accumulation, and heterophil infiltration in 4 tracheal cuts/bird within 4 microscopic fields/cut, located at $2,4,8$, and 10 clock positions. A score of 1 was assigned for each of the following tracheal tissue changes, namely, deciliation, mucosal hypertrophy, Goblet cell degeneration, and mucus accumulation, while a score of 0 was given to the absence of these tracheal changes. The average score of 4 fields/tissue section of 10 birds per group was used in statistical analysis. The same procedure was followed to compare the frequencies of mucus accumulation in lungs and fibroplasia in the right airsac.

The cumulative heterophil count in 12 fields ( 4 fields/ tissue section of each respiratory organ) was recorded. Microscopic images, magnified $1000 \times$, were taken of all recorded microscopic lesions for documentation.

\subsection{Amplification and Sequencing of Specific H9N2 Genome Segments}

The amplification and nucleotide sequencing of the HA1cleavage site and of neuraminidase (NA) stalk of P0, P1, $\mathrm{P} 2$, and $\mathrm{P} 3-\mathrm{H} 9 \mathrm{~N} 2$ viruses were concluded, according to previous procedures $[12,22]$ and to the manufacturer instructions provided by the Qiagen kits. Briefly, the H9N2-viral RNA was extracted from the allantoic fluids using the QIAamp Viral RNA Mini Kit (Qiagen, Germany). The extracted RNA from all passages was adjusted to $20 \mu \mathrm{g} / 50 \mu \mathrm{l}$ of the reaction mixture. The RNA was amplified by reverse transcription Polymerase Chain Reaction (PCR) using One-Step RT-PCR kit (Qiagen, Germany). The degenerate primers used for PCR amplification, targeting the cleavage site of the HA1 gene sequence, were the forward primer HU1 (5'TATGGGGCATACAYCAYCC-3') and the reverse primer HU2c (5'-TCTATGAACCCWGCWATTGCTCC-3') where $\mathrm{Y}=\mathrm{C}$ or $\mathrm{T}$ and $\mathrm{W}=\mathrm{A}$ or $\mathrm{T}$ [22]. Primers for NA stalk gene amplification were the forward primer NAF (5'GCAATTGGCTCTGTTTCTCT-3') and the reverse primer NAR (5'-CTTTGGTCTTCCTCTTATCA-3') [12]. The resulting DNA amplicons, with an expected length of 486 base pairs for HA1 and 1200 base pairs for NA stalk, were subjected to electrophoresis and visualized in $2 \%$ agarose gel using ethidium bromide staining.

The DNA amplicon was excised from the gel and purified with the QIAquick Gel Extraction kit (Qiagen, Germany). The nucleotide sequence of HA1 and NA stalk was determined for P0, P1, P2, and P3 viruses, recovered from each of the three organs of the broiler respiratory system, by using 3100 Avant Genetic AnalyzerABI PRISM (Applied Biosystems, Hitachi), and by the inclusion of the reverse HU2c and NAR primers for HA1 and NA stalk, respectively.

The amino-acid coding by the determined nucleotide sequences were determined and compared among the original (P0) and the differently passaged isolates of H9N2 (P1, P2, and P3), using the program of the NCBI website, known as Basic Local Alignment Search Tool (BLAST v. 2.2.15) (www.ncbi.nlm.nih.gov) [23].

\subsection{Statistics}

The frequencies of mortality, morbidity signs, gross lesions and embryonic recovery of H9N2 from different respiratory organs of broilers, at 3 days following challenge are compared among control and experimental broiler groups, challenged with differently passaged viruses, using the Chi-Square. The frequency of the microscopic lesions were compared using one way ANOVA and Tukey's test. Statistical analysis was performed using a Statistical Package for the Social Sciences program version 18 (SPSS Inc, Chicago).

\section{RESULTS AND DISCUSSION}

\subsection{Gradual Raise in Pathogenicity of Differently Passaged H9N2 in Broilers}

No mortality was observed among the control birds and those challenged with the differently passaged H9N2 viruses. The morbidity rate remained low $(<50 \%)$ with viral passaging, indicating that the virus did not acquire the "High Pathogenic" nature, as defined by the OIE, in which mortality should range between $20 \%$ to $60 \%$ while the morbidity rates rise over 50\% [5]. This low patho- genicity was associated with an absence of nasal discharge and occasional occurance of diarrhea in challenged birds. However, viral passaging resulted in higher pathological changes, leading to a significant increase in the frequency of birds showing specific morbidity signs namely swelling of infraorbital sinuses, conjunctivitis, and ocular exudates (Table 1, $\mathrm{P}<0.05$ ). Rales and sneezing are two typical signs of Low Pathogenic AI viruses [5,8]; actually, the two signs were seen in high frequency in birds challenged with P1H9N2 (10 birds/10 and 8 birds/10 showing sneezing and rales, respectively), and birds challenged with P2-H9N2 (10 birds/10 showing sneezing and rales), and P3-H9N2 birds ( 8 birds/10 and 10 birds/10 showing sneezing and 
Table 1. Frequency of broilers with specific morbidity signs at three days post H9N2 challenge.

\begin{tabular}{|c|c|c|c|c|c|c|c|c|c|}
\hline \multirow{2}{*}{$\begin{array}{c}\text { H9N2 } \\
\text { Passage } \\
\text { number }\end{array}$} & \multirow[b]{2}{*}{ Group } & \multicolumn{8}{|c|}{ Number of birds with specific signs/number tested } \\
\hline & & sneezing & SIOS $^{*}$ & Conjunctivitis & $\begin{array}{l}\text { Ocular } \\
\text { exudate }\end{array}$ & $\begin{array}{c}\text { Nasal } \\
\text { discharge }\end{array}$ & Rales & Diarrhea & Morbidity \\
\hline \multirow{2}{*}{$\mathrm{P} 1$} & Control & $1 / 10^{\mathrm{a}}$ & $0 / 10^{\mathrm{a}}$ & $0 / 10^{\mathrm{a}}$ & $0 / 10^{\mathrm{a}}$ & $0 / 10^{\mathrm{a}}$ & $0 / 10^{\mathrm{a}}$ & $0 / 10^{\mathrm{a}}$ & $0 / 10^{\mathrm{a}}$ \\
\hline & AI challenged & $10 / 10^{\mathrm{b}}$ & $1 / 10^{\mathrm{a}}$ & $1 / 10^{\mathrm{a}}$ & $4 / 10^{\mathrm{b}}$ & $0 / 10^{\mathrm{a}}$ & $8 / 10^{b}$ & $0 / 10^{\mathrm{a}}$ & $3 / 10^{\mathrm{a}, \mathrm{b}}$ \\
\hline \multirow{2}{*}{$\mathrm{P} 2$} & Control & $0 / 10^{\mathrm{a}}$ & $0 / 10^{\mathrm{a}}$ & $0 / 10^{\mathrm{a}}$ & $0 / 10^{\mathrm{a}}$ & $0 / 10^{\mathrm{a}}$ & $0 / 10^{\mathrm{a}}$ & $1 / 10^{\mathrm{a}}$ & $0 / 10^{\mathrm{a}}$ \\
\hline & AI challenged & $10 / 10^{\mathrm{b}}$ & $2 / 10^{a, b}$ & $6 / 10^{b}$ & $4 / 10^{b}$ & $0 / 10^{\mathrm{a}}$ & $10 / 10^{\mathrm{b}}$ & $2 / 10^{\mathrm{a}}$ & $4 / 10^{b}$ \\
\hline \multirow{2}{*}{ P3 } & Control & $0 / 10^{\mathrm{a}}$ & $0 / 10^{\mathrm{a}}$ & $0 / 10^{\mathrm{a}}$ & $0 / 10^{a}$ & $0 / 10^{\mathrm{a}}$ & $0 / 10^{\mathrm{a}}$ & $2 / 10^{\mathrm{a}}$ & $0 / 10^{\mathrm{a}}$ \\
\hline & AI challenged & $8 / 10^{\mathrm{b}}$ & $5 / 10^{\mathrm{b}}$ & $9 / 10^{b}$ & $10 / 10^{\mathrm{c}}$ & $0 / 10^{\mathrm{a}}$ & $10 / 10^{\mathrm{b}}$ & $3 / 10^{\mathrm{a}}$ & $3 / 10^{a, b}$ \\
\hline
\end{tabular}

${ }^{*}$ SIOS $=$ Swelling of infraorbital sinuses. ${ }^{\mathrm{a}-\mathrm{c}}$ Frequencies in a column with different alphabetic superscripts are significantly different $(\mathrm{P}<0.05)$.

Table 2. Frequency of broilers with specific gross lesions at three days post H9N2 challenge.

\begin{tabular}{|c|c|c|c|c|c|c|c|c|}
\hline \multirow{4}{*}{$\begin{array}{c}\text { H9N2 } \\
\text { Passage } \\
\text { number }\end{array}$} & \multirow{4}{*}{ Group } & \multicolumn{7}{|c|}{ Number of birds with specific lesions/number tested } \\
\hline & & \multirow{3}{*}{ Tracheitis } & \multicolumn{3}{|c|}{ Airsacculitis } & \multirow{3}{*}{ Lung congestion } & \multirow{3}{*}{ Pericarditis } & \multirow{3}{*}{ Enteritis } \\
\hline & & & \multicolumn{2}{|c|}{ Thoracic } & \multirow{2}{*}{ Abdominal } & & & \\
\hline & & & left & right & & & & \\
\hline \multirow{2}{*}{$\mathrm{P} 1$} & Control & $1 / 10^{\mathrm{a}}$ & $0 / 10^{\mathrm{a}}$ & $0 / 10^{\mathrm{a}}$ & $0 / 10^{\mathrm{a}}$ & $0 / 10^{\mathrm{a}}$ & $0 / 10^{\mathrm{a}}$ & $0 / 10^{\mathrm{a}}$ \\
\hline & AI challenged & $6 / 10^{\mathrm{b}}$ & $6 / 10^{\mathrm{b}}$ & $3 / 10^{a, b}$ & $0 / 10^{\mathrm{a}}$ & $0 / 10^{\mathrm{a}}$ & $0 / 10^{\mathrm{a}}$ & $0 / 10^{\mathrm{a}}$ \\
\hline \multirow{2}{*}{$\mathrm{P} 2$} & Control & $0 / 10^{\mathrm{a}}$ & $0 / 10^{\mathrm{a}}$ & $0 / 10^{\mathrm{a}}$ & $0 / 10^{\mathrm{a}}$ & $0 / 10^{\mathrm{a}}$ & $0 / 10^{\mathrm{a}}$ & $2 / 10^{a, b}$ \\
\hline & AI challenged & $6 / 10^{\mathrm{b}}$ & $7 / 10^{\mathrm{b}}$ & $7 / 10^{b, c}$ & $7 / 10^{\mathrm{b}}$ & $9 / 10^{b}$ & $0 / 10^{\mathrm{a}}$ & $1 / 10^{a, b}$ \\
\hline \multirow{2}{*}{ P3 } & Control & $1 / 10^{\mathrm{a}}$ & $0 / 10^{\mathrm{a}}$ & $0 / 10^{\mathrm{a}}$ & $0 / 10^{\mathrm{a}}$ & $0 / 10^{\mathrm{a}}$ & $0 / 10^{\mathrm{a}}$ & $0 / 10^{\mathrm{a}}$ \\
\hline & AI challenged & $7 / 10^{\mathrm{b}}$ & $9 / 10^{b}$ & $8 / 10^{c}$ & $3 / 10^{\mathrm{a}, \mathrm{b}}$ & $9 / 10^{b}$ & $0 / 10^{\mathrm{a}}$ & $4 / 10^{b}$ \\
\hline
\end{tabular}

${ }^{\mathrm{a}-\mathrm{c}}$ Frequencies in a column with different alphabetic superscripts are significantly different $(\mathrm{P}<0.05)$.

rales, respectively) (Table 1). It is worth noting that the frequency of morbidity signs in control-unchallenged birds, included in the P1, P2, and P3 trials, was almost absent; this result provided an indication of the success of precautions followed in the isolation pens used for rearing the different groups.

The frequency of birds showing specific gross lesions following challenges with P1, P2, and P3-H9N2 is presented in Table 2. Following viral passaging, the H9N2 viruses had their significant cytopathic effects in the right thoracic and abdominal airsacs in P2 and P3challenged birds as compared to P1-challenged birds ( $\mathrm{P}$ $<0.05)$. There was a trend of an increase in the frequency of birds showing left airsacculitis following viral passaging $(6 / 10,7 / 10$, and $9 / 10$ in $\mathrm{P} 1, \mathrm{P} 2$, and P3-challenged birds respectively, $\mathrm{P}>0.05)$. These results indicate the ability of $\mathrm{H} 9 \mathrm{~N} 2$ passaging to induce higher pathological changes in the host tissues, specifically airsacs. This viral adaptation to the lower respiratory tract tissue was further reflected by an abrupt increase in the frequency of birds showing lung congestion [(9/10 in P2 and P3 versus $0 / 10$ in $\mathrm{P} 1$ challenged birds $)(\mathrm{P}<0.05)]$. The $\mathrm{H} 9 \mathrm{~N} 2$ passaging resulted in a significant increase in frequency of challenged birds showing enteritis in the P3 compared to $\mathrm{P} 1$-birds $(\mathrm{P}<0.05)$. The dissemination and adaptation of H9N2 to the digestive tract cells indicates that the virus acquired new tissue tropism towards enteric cells that have a mixture of furin-like and trypsin-like proteases $[1,8]$. The LPAI-H9N2 virus seems to have high ability to infect the tracheal cells resulting in a high frequency of challenged birds that showed tracheitis
(6/10 in P1, and P2 challenged birds, and 7/10 in P3 challenged birds, $\mathrm{P}>0.05$, Table 2 ). Such results could be due to the presence of trypsine-like enzyme in the epithelial cells of the trachea which might cleave the HA 0 of H9N2 viruses to HA1 and HA2, rendering the virus infective [8]. The viral passaging did not affect the pericardium, since no pericarditis was observed in all of the experimental birds. It is worth noting that only the HPAI viruses are able to induce cardiovascular damage following viraemia, oedema and congestion of the cardiac integuments $[5,14,16]$; the pericarditis can exist in mixed infection of AI viruses with respiratory pathogens that enhance the H9N2 dissemination and infection in heart tissues, including co-infection with Mycoplasma gallisepticum [19,20], Haemophilus paragallinarum and Staphylococcus aureus [21]. Moreover, the absence of pericarditis could have helped the challenged birds to survive fully $(100 \%)$ and to manifest a morbidity lower than the 50\% frequency (Table 1).

Histopathologic changes in respiratory organs of challenged birds are presented in Table 3. There was an insignificant difference in the frequency of birds showing deciliation, Goblet cells degeneration, and mucus accumulation (Figure 1) following challenges with differently passaged H9N2.

The high frequency of challenged birds showing tracheitis (Table 2) could be a result of the efficient viral dissemination in an infection site that is rich in trypsinlike proteases. These enzymes enable the virus to replicate easily in the epithelial tracheal cells causing deciliation, destruction of Goblet cells through cytolysis and 
Table 3. Histopathologic lesions in three respiratory organs of broilers at 3 days post challenge with differently passaged H9N2 virus.

\begin{tabular}{|c|c|c|c|c|c|c|c|c|c|}
\hline \multirow{3}{*}{$\begin{array}{l}\text { H9N2 } \\
\text { Passage } \\
\text { number }\end{array}$} & \multirow{3}{*}{ Group } & \multicolumn{3}{|c|}{$\begin{array}{l}\text { Number of infiltrated Hetero- } \\
\text { phils/tissue section }\end{array}$} & \multicolumn{5}{|c|}{$\%$ of fields/tissue section ${ }^{* *}$ showing a specific lesion in each of the three organs } \\
\hline & & \multirow[b]{2}{*}{ Trachea } & \multirow[b]{2}{*}{ Lung } & \multirow{2}{*}{$\begin{array}{l}\text { Right } \\
\text { thoracic } \\
\text { airsac }\end{array}$} & \multicolumn{3}{|c|}{ Trachea } & \multirow{2}{*}{$\begin{array}{c}\text { Lung } \\
\text { Mucus } \\
\text { accumulation } \\
\text { in airducts }\end{array}$} & Right thoracic airsac \\
\hline & & & & & Deciliation & $\begin{array}{l}\text { Goblet cells } \\
\text { degeneration }\end{array}$ & $\begin{array}{c}\text { Mucus } \\
\text { accumulation }\end{array}$ & & Fibroplasia \\
\hline \multirow{2}{*}{ P1 } & Control & $0^{\mathrm{a}}$ & $1^{\mathrm{a}}$ & $0^{\mathrm{a}}$ & $7.5^{\mathrm{a}}$ & $4.2^{\mathrm{a}}$ & $3.3^{\mathrm{a}}$ & $3.3^{\mathrm{a}}$ & $0.0^{\mathrm{a}}$ \\
\hline & AI challenged & $15^{\mathrm{b}}$ & $1^{\mathrm{a}}$ & $4^{\mathrm{b}}$ & $81.7^{\mathrm{b}}$ & $85.8^{\mathrm{b}}$ & $72.5^{\mathrm{b}}$ & $57.5^{\mathrm{b}}$ & $50.0^{\mathrm{b}}$ \\
\hline \multirow{2}{*}{ P2 } & Control & $0^{\mathrm{a}}$ & $1^{\mathrm{a}}$ & $0^{\mathrm{a}}$ & $10.0^{\mathrm{a}}$ & $4.2^{\mathrm{a}}$ & $4.2^{\mathrm{a}}$ & $0.0^{\mathrm{a}}$ & $0.0^{\mathrm{a}}$ \\
\hline & AI challenged & $21^{\mathrm{c}}$ & $2^{\mathrm{a}}$ & $4^{\mathrm{b}}$ & $92.5^{\mathrm{b}}$ & $88.3^{\mathrm{b}}$ & $73.3^{\mathrm{b}}$ & $53.3^{\mathrm{b}}$ & $60.0^{\mathrm{b}}$ \\
\hline \multirow{2}{*}{ P3 } & Control & $0^{\mathrm{a}}$ & $1^{\mathrm{a}}$ & $0^{\mathrm{a}}$ & $5.8^{\mathrm{a}}$ & $0.0^{\mathrm{a}}$ & $0.0^{\mathrm{b}}$ & $0.0^{\mathrm{a}}$ & $0.0^{\mathrm{a}}$ \\
\hline & AI challenged & $23^{\mathrm{c}}$ & $2^{\mathrm{a}}$ & $3^{\mathrm{b}}$ & $92.5^{\mathrm{b}}$ & $90.8^{\mathrm{b}}$ & $73.3^{\mathrm{b}}$ & $55.8^{\mathrm{b}}$ & $60.0^{\mathrm{b}}$ \\
\hline
\end{tabular}

${ }^{a-c}$ Frequencies in a column with different alphabetic superscripts are significantly different $(\mathrm{P}<0.05)$; *Average number of infiltrated heterophils in 4 microscopic fields/tissue section observed at clock position $2,4,8$, and 10 , and at $1000 \times$ magnification; ${ }^{* *}$ Average percentage of 4 microscopic fields/tissue section showing positive lesion, and observed at clock position $2,4,8$, and 10 , and at $1000 \times$ magnification.

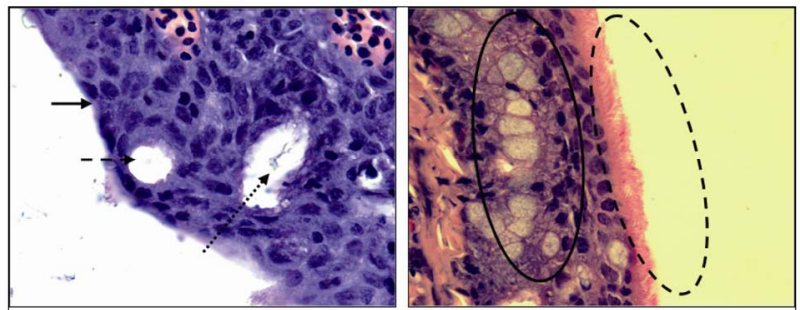

Figure 1. A microscope slide photograph of deciliation (arrow), Goblet cells degeneration (dashed arrow), and mucus accumulation (dotted arrow) in tracheas of P3-challenged birds (left image) versus normal ciliation (dashed oval), presence of intact Goblet cells (oval), and absence of mucus accumulation in tracheas of control birds (right image). (H \& E stain, 1000× magnification).

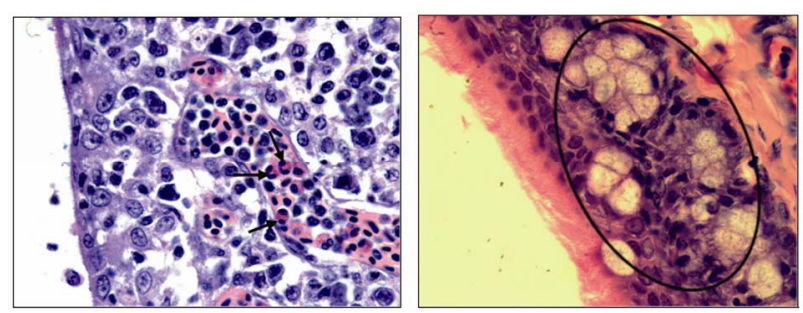

Figure 2. A microscope slide photograph of heterophils infiltration (arrows) in tracheal tissues of P3-challenged birds (left image) versus absence of heterophils (oval) in tracheas of control birds (right image). (H \& E stain, 1000× magnification).

release of virions $[14,15,17,24]$, and mucus accumulation in necrotic areas $[14,15,17]$. There was significant increase of tracheal heterophils following viral passaging from 15 heterophils/tissue section in $\mathrm{P} 1$, to 21 , and 23 heterophils/tissue section in $\mathrm{P} 2$, and $\mathrm{P} 3$, respectively (Table 3, Figure 2, $\mathrm{P}<0.05$ ). Previous workers related the increase of heterophil counts to the accumulation of Reactive Oxygen Species (ROS) following necrosis of the epithelial and parenchymal cells of the trachea, leading to subsequent inflammation [25]. Moreover, the increased heterophil numbers in the trachea might enhance viral dissemination, since AI viruses are proven to use the immune cells, namely heterophils and macrophages, as vehicles to reach to different host body tissues $[5,8]$. No significant differences were observed in the frequency of mucus accumulation in the lung airducts or in the fibroplasia of the right airsac among challenged birds $(\mathrm{P}>0.05)$. However, these observations were significantly different between challenged and control birds, as presented in Table 3 and the documentation of images in Figures 3 and 4.

These findings are inducive for future investigations targetting higher number of passages of H9N2, which might enable these viruses to infect the lower respiratory tract parenchyma, including the lungs and airsacs. It is worth noting that the low heterophils infiltration in these two organs is indicative of the low infectivity of the passaged H9N2 viruses, since the heteropils are known to be present in respiratory tissues in advanced stages of inflammation and infection [26,27]. The H9N2 recovery
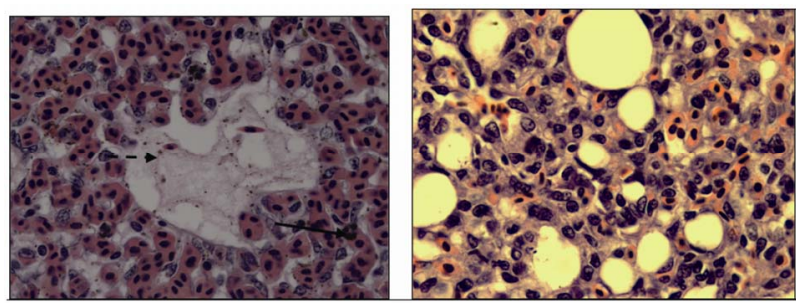

Figure 3. A microscope slide photograph showing few heterophils infiltration in the lung parenchyma (arrow) and mucus accumulation in the lung airducts (dashed arrow) of P3-challenged birds (left image) versus absence of heterophils or mucus accumulation in the lungs of control birds (right image). (H \& E stain, $1000 \times$ magnification). 

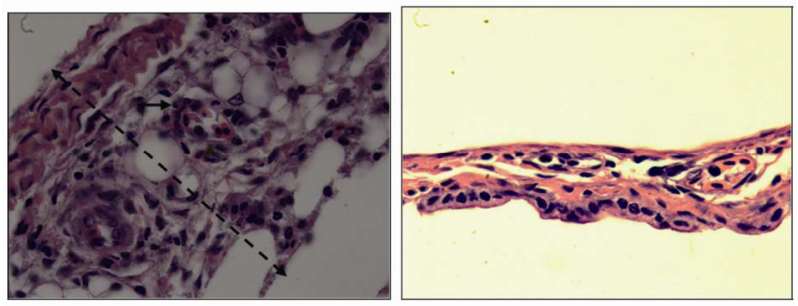

Figure 4. A microscope slide photograph showing fibroplasia (dashed arrow) and few heterophils infiltration in the airsac (arrow) of P3-challenged birds (left image) versus absence of fibroplasia or heterophils infiltration in the airsac of control birds (right image). (H \& E stain, 1000× magnification).

Table 4. Recovery ${ }^{*}$ frequency of differently passaged H9N2 viruses from different respiratory organs.

\begin{tabular}{ccccc}
\hline \multirow{2}{*}{$\begin{array}{c}\text { H9N2 } \\
\text { Passage } \\
\text { number }\end{array}$} & Group & \multicolumn{3}{c}{ Recovery frequency of } \\
H9N2 viruses
\end{tabular}

*The recovery is based on presence of HA activity in the allantoic fluids of chicken embryos inoculated before 3 days with individual homogenates of the respective respiratory organs of broilers challenged with differently passaged $\mathrm{H} 9 \mathrm{~N} 2$ virus (P1, P2, or P3); ${ }^{a}$ Frequencies in a row with the same alphabetic superscripts are not significantly different $(\mathrm{P}>0.05) ;{ }^{1,2}$ Frequencies in a column with different arabic numerical superscripts are significantly different $(\mathrm{P}<0.05)$

from the three examined organs of the respiratory system was similarly high in birds challenged with the differently passaged viruses (Table $4, \mathrm{P}>0.05$ ). These results indicate the nature of the extended dissemination of
H9N2 virus in the whole respiratory system. However, a low pathologic effect by the H9N2 virus was observed in the lungs and airsac of the P0-challenged birds, as reflected in the observed gross and microscopic lesions, revealing the significant impact of passaging on gradual raise of pathogenicity in specific respiratory organs, regardless of the similar frequency of recovery of such viruses from the examined tissues.

\subsection{Cleavage Site of HA1 and Neuraminidase Stalk Sequences in H9N2}

RT-PCR amplification of a part of HA1 and NA stalk of the extracted RNA of H9N2 recovered from allantoic fluid of eggs that were inoculated with the differently passaged broiler-tracheal isolates, are presented in Figures 5 and 6 . These results confirm the presence of positive H9N2 viruses with a 486 bp length amplicon for HA1 and a $1200 \mathrm{bp}$ length amplicon for NA stalk. The amino acid sequence concluded from a part of HA1 nucleotide sequencing, ranging between position 265 to 338 was GHILSGGSHGRILKTDLKSGNCVVQCQTE KGGLNSTLPFHNISKYAFGTCPKYIRVKSLKLAVG MRNVPARSSR, a typical sequence present in P1, P2, and P3-H9N2 viruses. The presence of the above conserved HA0 cleavage site motif PARSSR, with two basic Arginine amino acids, renders this part of genome not correlating with the higher frequency of morbidity signs, gross and microscopic lesions observed with more passaging of the H9N2. Similar results were obtained in previous literature, reporting varying pathogenicity of H9N2 with a stable-conserved PARSSR cleavage site motif in different outbreaks of Asian and Middle eastern countries [3,7]. The number of HA1 glycosilation sites was also stable in the differently passaged H9N2 namely,

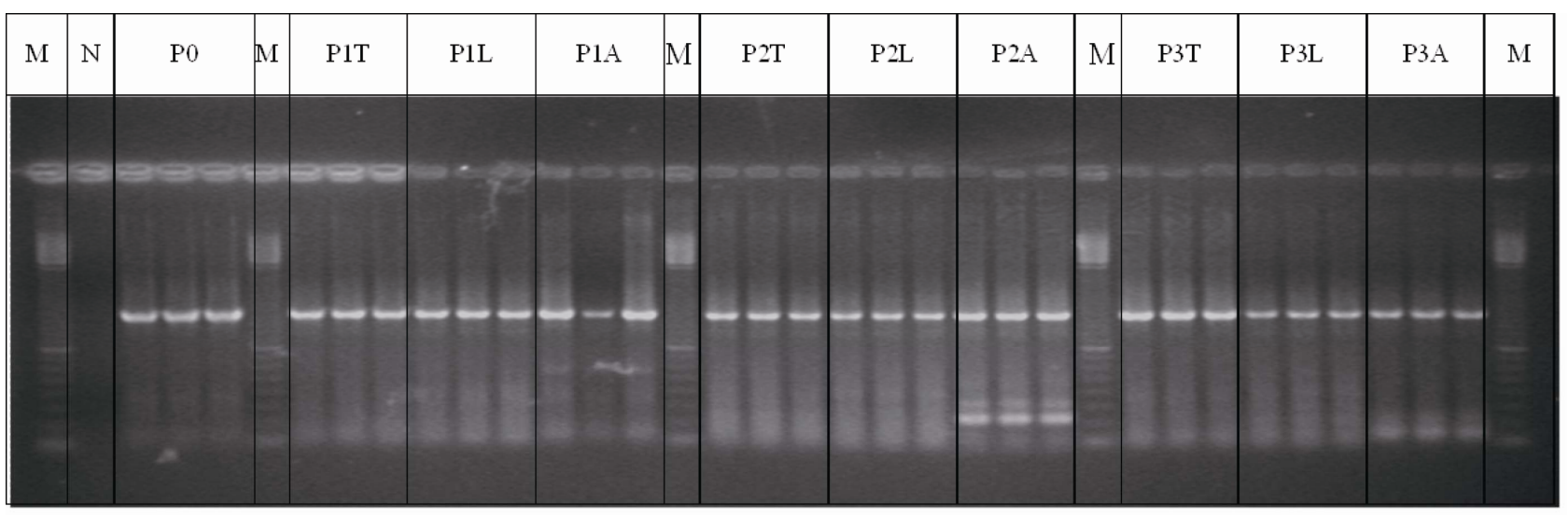

Figure 5. PCR amplification of the HA1 gene of the experimental viruses. P0 = original A/chicken/Lebanon1/2004 H9N2 isolate. P1T, P1L, P1A = once passaged H9N2 virus, recovered from trachea, lung, and right airsac of 21-day-old broilers, respectivey. P2T, P2L, P2A = twice passaged H9N2 virus, recovered from trachea, lung, and right airsac of 21-day-old broilers, respectively. P3T, P3L, $\mathrm{P} 3 \mathrm{~A}=$ three times passaged H9N2 virus, recovered from trachea, lung, and right airsac of 21-day-old broilers, respectively. $\mathrm{M}=100$ base pair molecular marker. $\mathrm{N}=$ negative control. 


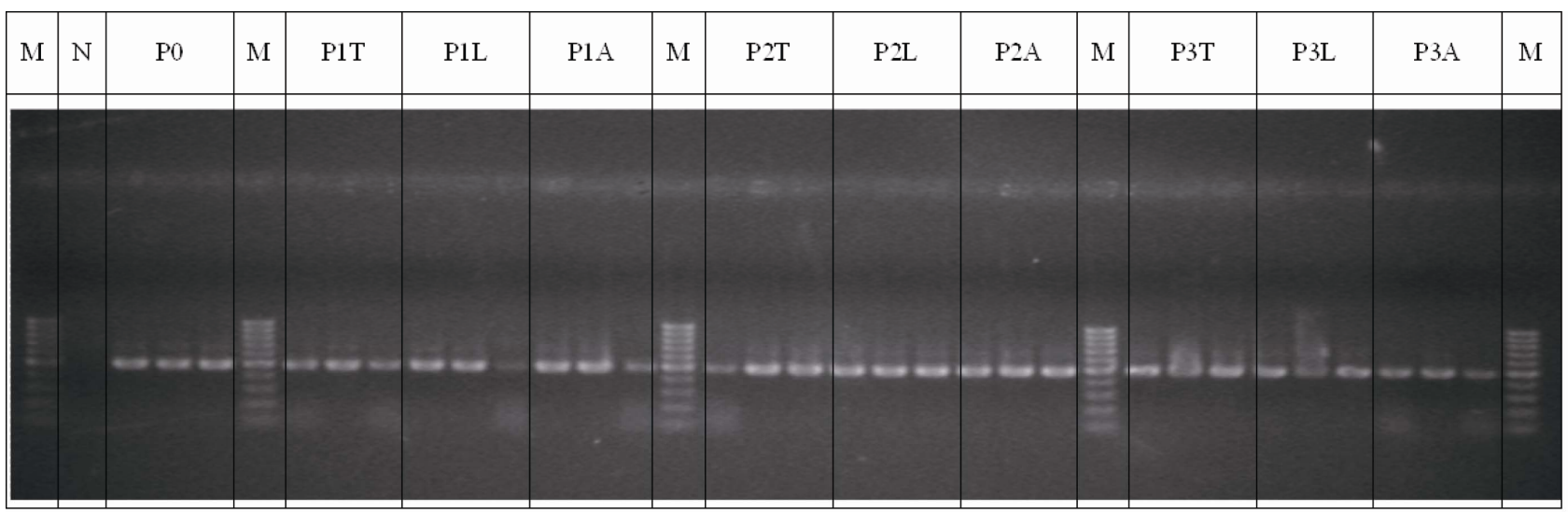

Figure 6. PCR amplification of the NA stalk gene of the experimental viruses. P0 = original A/chicken/Lebanon1/2004 H9N2 isolate. P1T, P1L, P1A = once passaged H9N2 virus, recovered from trachea, lung, and right airsac of 21-day-old broilers, respectivey. P2T, P2L, P2A = twice passaged H9N2 virus, recovered from trachea, lung, and right airsac of 21-day-old broilers, respectively. P3T, P3L, $\mathrm{P} 3 \mathrm{~A}=$ three times passaged H9N2 virus, recovered from trachea, lung, and right airsac of 21-day-old broilers, respectively. $\mathrm{M}=100$ base pair molecular marker. $\mathrm{N}=$ negative control.

the NIS and NST at amino acid position 308 and 314, rendering an absence of the correlation between glycosilation sites and the higher frequencies in pathologic effects seen with more passaging. These results disagree with previous reported literature, indicating that a decrease in number of glycosilation sites results in an increase of pathogenicity of $\mathrm{H} 5 \mathrm{~N} 1, \mathrm{H} 7$, and $\mathrm{H} 9 \mathrm{~N} 2$ viruses [1].

The amino acid sequence deducted from the nucleotide sequence of a part of NA stalk (amino acid position from 32 to 104) is presented in Table 5. None of the passaged viruses, and regardless of its respiratory organ source, did show any amino acid deletion at position 38 39 and 63 - 65 of the NA stalk. P1 viruses showed an 85 to 97 similarity percentage with the original $\mathrm{P} 0$ virus indicating a high mutagenic potential of $\mathrm{H} 9 \mathrm{~N} 2$ at the NA stalk a.a sequence. The similarity percentage of the $\mathrm{P} 2$ to P0 viruses was reduced to $83 \%-96 \%$. These a.a changes were observed in two segments of the NA stalk namely from K38 to V51 and from L68 to C78. However, P3 viruses, which were highly adaptable to the broiler respiratory tissues (Tables 2 and 3), showed the least NA amino acid sequence difference to that observed in the original P0 virus. In relation to the NA a.a. sequence of $\mathrm{P} 0$ viruses, the $\mathrm{P} 3$ viruses, recovered of the broiler tracheas, showed a single substitution of arginine with proline positioned at 46 , while the $\mathrm{P} 3$ viruses, recovered from lungs and right airsacs, showed an additional substitution of asparagine with lysine positioned at 47 . Consequently, the pathogenicity of H9N2 seems to be dependant on a single a.a. substitution of Arginine with Proline positioned at 46 in the a.a sequence of NA stalk. Deletions in the NA stalk of H9N2 positioned at 38 - 39 and 63 - 65 were not detected in this work, unabling the establishment of a relationship between deletions in NA stalk to the observed gradual raise in pathogenicity of H9N2. However, previous work related such deletions to adaptability of this virus to human hosts $[1,28]$. It is worth noting that a.a deletions at these positions resulted in highly pathogenic H9N2 virus development in ducks, with a reported strain identity known as $\mathrm{Dk} / \mathrm{HK} / \mathrm{Y} 280 / 97$ [1].

\section{CONCLUSIONS}

The three-fold serial passaging of H9N2 virus in 21days-old broilers caused an increase in gross lesions, specifically in the lower respiratory tract and the intestines, and resulted in an increase of heterophil count in tracheal tissues of the challenged birds. However, the three viral passages didn't convert the LPAI-H9N2 to a HPAIH9N2 virus. This was reflected by the low mortality and morbidity rates observed in birds challenged with $\mathrm{P} 1, \mathrm{P} 2$, and P3 viruses. Future studies should include different inoculation routes, additional viral passaging and coinfections strategies to help in establishing a wider view of the factors affecting the H9N2 pathogenicity in broilers. The analysis of the amino acid sequence concluded from a part of HA1 nucleotide sequencing between 265 to 338 position revealed a conserved nature among all of the passaged viruses (R-S-S-R), a cleavage site that is present in most Asian and Middle Eastern recovered isolates of H9N2. The presence of such a conserved motif and conserved glycosilation sites in differently passaged H9N2, varying in their pathologic effect, eliminates the concept of relatedness of pathogenicity to HA1 cleavage site and/or glycosilation sites. A future sequence analysis of HA2, which is responsible for viral fusion with the host cell, following neuraminidase activity, 
Table 5. Amino acid sequences of a part of the neuraminidase stalk of the differently passaged H9N2 viruses (a.a position 32 - 104).

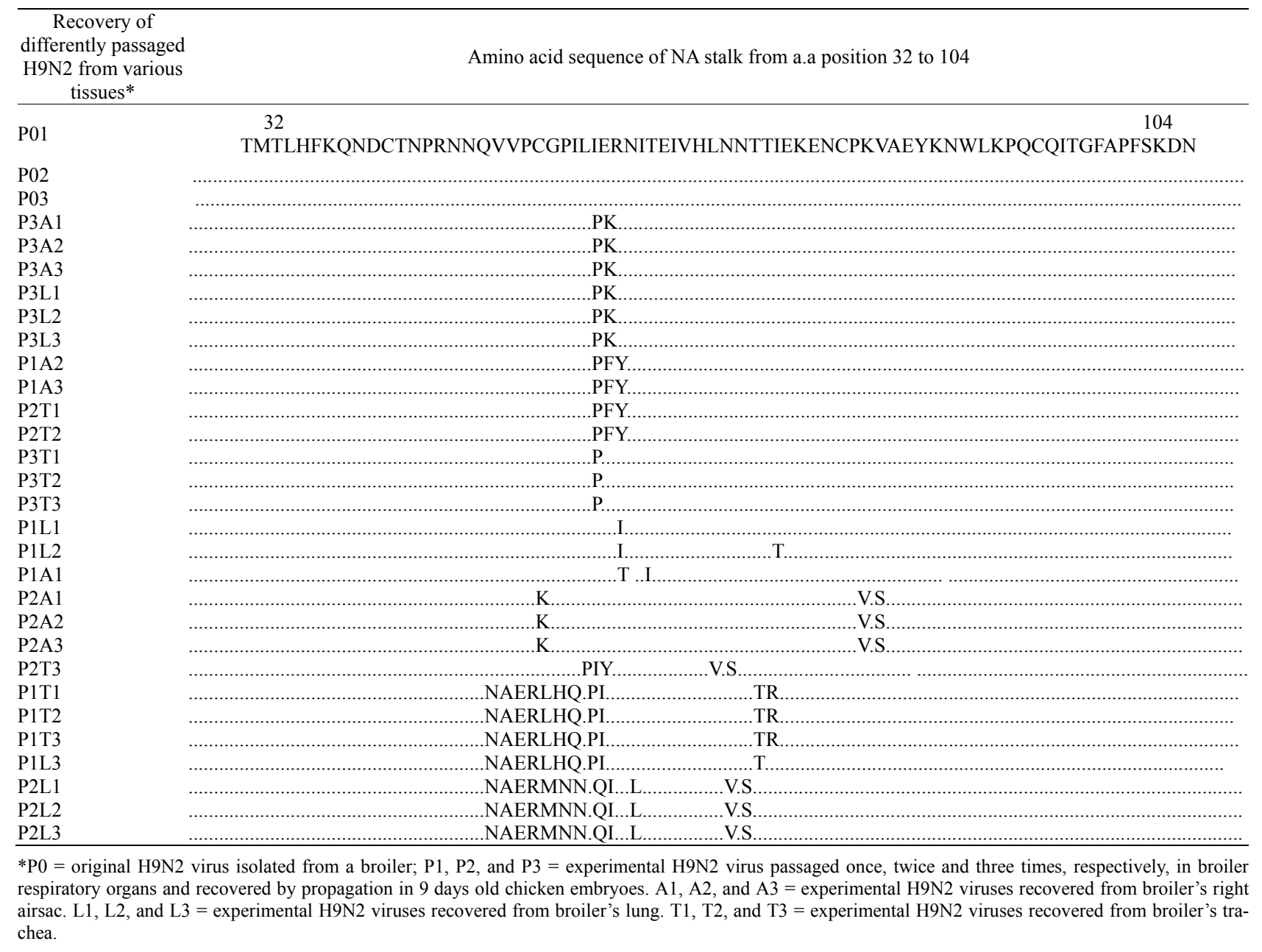

would be important to understand the role of the total HA protein in the H9N2 pathogenicity.

The neuraminidase stalk showed an a.a sequence variability among the differently passaged viruses. However viruses with different pathologic effects, namely P0 and P3 showed the highest amino acid sequence similarity, with one amino acid substitution. These findings indicate, most likely, the relatedness of a single amino acid substitution of Arginine to serine positioned at 46 in the NA stalk to viral pathogenicity. Moreover, no deletion was observed in a.a position $63-65$ and 38 - 39 in P2 and P3 viruses, in spite of the higher morbidity, and gross and microscopic lesions to broilers respiratory tissues, caused by these two passaged isolates. Consequently, the pathogenicity of H9N2 seems to be unrelated to deletions in the NA stalk. A detailed study of the potential of a.a. variability in the NA stalk should be investigated in the future, in terms of its relatedness to gradual augmentation of the pathogenicity in H9N2 viruses. The deletions in the NA stalk could be responsible for the adaptation of the H9N2 viruses to different host species, a hypothesis that will be investigated in our future research

\section{REFERENCES}

[1] Guo, Y.J., Krauss, S., Senne, D.A., Mo, I.P., Lo, K.S., Xiong X.P., Norwood, M., Shortridge, K.F., Webster R.G. and Guan Y. (2000) Characterization of the pathogenicity of members of the newly established H9N2 influenza virus lineages in Asia. Virology, 267, 279-288.

doi:10.1006/viro.1999.0115

[2] Barbour, E.K., Sagherian, V.K., Sagherian, N.K., Dankar, S.K., Jaber, L.S., Usayran, N.N. and Farran, M. T. (2006) Avian Influenza outbreak in poultry in the Lebanon and transmission to neighbouring farmers and swine. Veterinaria Italiana, 42, 13-21.

[3] Banet-Noach, C., Perk, S., Simanov, L., Grebenyuk, N., Rozenblut, E., Pokamunski, S., Pirak, M., Tendler, Y. and Panshin, A. (2007) H9N2 influenza viruses from Israeli poultry: A five-year outbreak. Avian Diseases, 51, 290296. doi:10.1637/7590-040206R1.1 
[4] Barbour, E.K., Shaib, H.A. and Rayya, E.G. (2007) Reverse transcriptase-polymerase chain reaction-based surveillance of type A influenza viruses in wild and domestic birds of the Lebanon. Veterinaria Italiana, 43, 33-41.

[5] Pantin-Jackwood, M.J. and Swayne, D.E. (2009) Pathogenesis and pathobiology of avian influenza virus infection in birds. Revue Scientifique et Technique/Office Internationale des Epizooties, 28, 113-136.

[6] Ito, T., Goto, H., Yamamoto, E., Tanaka, H., Takeuchi, M., Kuwayama, M., Kawaoka, Y. and Otsuki, K. (2001) Generation of a highly pathogenic avian influenza A virus from an avirulent field isolate by passaging in chickens. Journal of Virology, 75, 4439-4443.

doi:10.1128/JVI.75.9.4439-4443.2001

[7] Shaib, H.A., Cochet, N., Ribeiro, T., Abdel, N.A.M., Nemer, G. and Barbour, E.K. (2010) Impact of embryonic passaging of H9N2 virus on pathogenicity and stability of HA1-amino acid sequence cleavage site. Medical Science Monitor, 16, 333-337.

[8] Swayne, D.E. and Halvorson, D.A. (2008) Influenza. In: Saif, Y.M., Barnes, H.J., Fadly, A.M., Glisson, J.R., McDougald, L.R. and Swayne, D.E. Eds., Diseases of Poultry, 12th Edition, Iowa State University Press, Iowa, 153-184.

[9] Ebrahimi, S.M., Nili, H. and Sohrabi, N. (2010) Histopathological evaluation of A/chicken/Iran/339/02(H9N2), an Iranian field isolate of influenza virus, on Japanese quail (Coturnix coturnix japonica). World Applied Sciences Journal, 9, 226-229.

[10] Lee, D.C.W., Mok, C.K.P., Law, A.H.Y., Peiris, M. and Lau, A.S. (2010) Differential replication of avian influenza H9N2 viruses in human alveolar epithelial A549 cells. Virology Journal, 7, 71-75. doi:10.1186/1743-422X-7-71

[11] Kianizadeh, M., Pourbakhch, S.A., Toroghi, R. and Momayez, R. (2006) Pathogencitiy and haemagglutinin gene sequence analysis of Iranian avian influenza H9N2 viruses isolated during 1998-2001. Iranian Journal of Veterinary Research, 7, 37-41.

[12] Liu, J., Okazaki, K., Shi, W., Wu, Q.M., Mweene, A.S. and Kida, H. (2003) Phylogenetic analysis of neuraminidase gene of H9N2 influenza viruses prevalent in chickens in China during 1995-2002. Virus Genes, 27, 197202. doi:10.1023/A:1025736829103

[13] Bano, S., Naeem, K. and Malik, S.A. (2003) Evaluation of pathogenic potential of avian influenza virus serotype H9N2 in chickens. Avian Diseases, 47, 817-822. doi:10.1637/0005-2086-47.s3.817

[14] Mosleh, N., Dadras, H. and Mohammadi, A. (2009). Evaluation of H9N2 avian influenza virus dissemination in various organs of experimentally infected broiler chickens using RT-PCR. Iranian Journal of Veterinary Research, 10, 12-20.

[15] Pazani, J., Marandi, M.V., Ashrafihelan, J., Marjanmehr, S.H. and Ghods, F. (2008) Pathological studies of A/ chicken/Tehran/ZMT-173/99 (H9N2) influenza virus in commercial broiler chickens of Iran. International Journal of Poultry Science, 7, 502-510. doi:10.3923/ijps.2008.502.510

[16] Gharaibeh, S. (2008) Pathogenicity of an avian influenza virus serotype H9N2 in chickens. Avian Diseases, 52,
106-110. doi:10.1637/8108-090907-Reg

[17] Swayne, D.E., Senne, D.A. and Suarez, D.L. (2008) Avian influenza. A Laboratory Manual for the Isolation and Identification of Avian Pathogens, 5th Edition, American Association of Avian Pathologists, Kennett Square, 128-134.

[18] Senne, D.A. (1998) Virus propagation in embryonating eggs. In: Swayne, D., Glisson, J.R., Jackwood, M.W., Pearson, J.E. and Reed, W.M. Eds., A Laboratory Manual for the Isolation and Identification of Avian Pathogens, 4th Edition, American Association of Avian Pathologists, New Bolton Center, Kennett Square, 235-247.

[19] Barbour, E.K., El-Hakim, R.G., Kaadi, M.S., Shaib, H., Gerges, D.D., Nehme, P.A. and Harakeh, S. (2006) Pathology of the respiratory system in essential oil-treated broilers following a challenge with mucosal bacterium and/or a haemagglutinating virus. Journal of the American Holistic Veterinary Medical Association, 25, 15-30.

[20] Kishida, N., Eto, M., Sunaga, Y. and Kida, H. (2004) Enhancement of pathogenicity of H9N2 influenza A viruses isolated from chicken in China by co-infection with Staphylococcus aureus and Haemophilus paragallinarum. International Congress Series, 263, 481-485. doi:10.1016/j.ics.2004.01.033

[21] Garcia-Sastre, A. (2010) Influenza virus receptor specificity: Disease and transmission. American Journal of Pathology, 176, 1584-1585. doi:10.2353/ajpath.2010.100066

[22] Banks, J., Speidel, E.C., Harris, P.A. and Alexander, D.J. (2000) Phylogenetic analysis of influenza A viruses of H9 haemagglutinin subtype. Avian Pathology, 33, 353-360. doi:10.1080/03079450050118485

[23] Altschul, S., Gish, W., Miller, W., Meyers, E.W. and Lipman, D.J. (1990) Basic local alignment search tool. Journal of Molecular Biology, 215, 403-410.

[24] Barbour, E.K., El-Hakim, R.G., Kaadi, M.S., Shaib, H.A., Gerges, D.D. and Nehme, P.A. (2006) Evaluation of the histopathology of the respiratory system in essential oil treated broilers following a challenge with Mycoplasma gallisepticum and/or H9N2 influenza virus. International Journal of Applied Research in Veterinary Medicine, 4, 293-300.

[25] Fedson, D.S. (2009) Confronting the next influenza pandemic with anti-inflammatory and immunomodulatory agents: Why they are needed and how they might work. Influenza and Other Respiratory Viruses, 3, 129-142. doi:10.1111/j.1750-2659.2009.00090.x

[26] Ewbank, J. (2008) Innate immunity. Humana Press, Totowa, 458.

[27] Swaggerty, C., Kaiser, P., Rothwell, L., Pevzner, I.Y. and Kogut, M.H. (2006) Heterophil cytokine mRNA profiles from genetically distinct lines of chickens with differential heterophil mediated innate immune responses. Avian Pathology, 35, 102-108. doi:10.1080/03079450600597535

[28] Soltanialvar, M., Shoushtari, H., Bozorgmehrifard, M., Charkhkar, S. and Eshratabadi, F. (2010) Molecular characterization of hemagglutinin and neuraminidase genes of H9N2 avian influenza viruses isolated from commercial broiler chicken in Iran. Journal of Biological Sciences, 10, 145-150. doi:10.3923/jbs.2010.145.150 